\title{
Present Situation of Sports of Rural School in Northwest Region
}

\author{
Bo Yang ${ }^{1, a}$, Xiao-bin Chen ${ }^{2, b}$ \\ 'Biyushitan Primary School of Tongwei County, Dingxi Gansu 743315, China; \\ ${ }^{2}$ Wenmiao Street Primary School of Tongwei County, Dingxi Gansu 743300, China. \\ a617146885@qq.com, ${ }^{\text {b } 1632546547 ~ @ q q . c o m ~}$
}

Keywords: Rural Schools, Sports Study, Development, Countermeasure .

\begin{abstract}
The article applied the research methods of interview, questionnaire survey, literature etc to seriously study the aspects of development state, teaching staff construction etc for sports of rural school in northwest region. The study concluded: $18 \%$ of schools have no sports teaching. 12\% of schools are in casual condition. The rate changing from sports into other classes is high up to $37.5 \%$. $34 \%$ of the primary schools teach according to the new curriculum standard. $33.56 \%$ of middle schools teach according to the new curriculum standard. The curriculum provision mainly uses athletics events of track and field, ball games etc filling contents. Short teaching staff. The ratio between teachers and students is 1:500 in junior middle school. The constitution and physical condition of students are not optimistic. The physical constitution decreases continuously. The sports facilities, equipment and fund are deficient seriously. The rate of reaching standard for equipment is $39.1 \% .21 .04 \%$ of schools have no basketball, volleyball and football field. Hence the author suggests: 1 . reinforce the study of leaders of all levels of education administrative department, improve their ideas and understanding. 2. Establish and complete the supervision system, monitoring system of physical constitution of students and sports examination evaluation system for rural schools. 3. Reinforce the construction of teaching staff of rural sports. 4. All levels of education administrative department should increase the input of school sports fund. 5. Sports teacher of rural schools should strengthen the professional skills and moral cultivation.
\end{abstract}

\section{Introduction}

In 1917 Mao Ze-Dong has already published one thesis named "Sports Study" on the magazine of "New Youth", which comprehensively and deeply elaborated the significance of sports to adolescent grow and nation develop healthily. He deeply worried about "the physical constitution of nation decrease gradually", thought that "three cultivations are emphasized, however formerly for students, moral and intelligence are more important than sports", loudly appealed the importance of sports. He even had a deep thought about school sports, pointed out "in primary school, we should focus on the body growth, afterwards are knowledge increase and moral cultivation". "In middle school the study should emphasize all three cultivations, but intelligence is emphasized more nowadays". In "education promoting plan to $21^{\text {st }}$ century" suggested by national education ministry, clearly said that work focus of school sports should transfer to the rural and less developed area. Yet, at present actual economic condition of national rural is still poor. Various aspects are in state of backwardness. Especially the actual condition of sport education of middle and primary school in vast rural area is even more worrying, which has a big gap compared with sports education of middle and primary school in national cities.

\section{Research Method and Object}

\subsection{Using Questionnaire Survey}

Questionnaire survey for teachers: in Gansu, Ningxia, Qinghai, Shaanxi, Xinjiang five provinces, each randomly choose five rural schools. Every school was mailed with 6 pieces of questionnaire survey paper, 150 papers in total, retrieved 180 pieces of valid questionnaire survey paper. Recovery is $84 \%$. 
Questionnaire survey for students: in Gansu, Ningxia, Qinghai, Shaanxi, Xinjiang five provinces, each randomly choose five rural schools. Every school was mailed with 10 pieces of questionnaire survey paper, 250 papers in total, retrieved 180 pieces of valid questionnaire survey paper. Recovery is $72 \%$. 2.2Literature Method

According to the purpose and content of research studied more than 10 papers of relative literature through the library of Northwest Normal University.

2.3Interview Method

By the opportunity of correspondence study, primarily interviewed some rural sports teachers in Gansu province $(08,09,10$ grade students of adult education department of Northwest Normal University) for the actual condition of sports of rural schools.

\section{Research Results and Analysis}

\subsection{Situation of Sports Class}

The research shows, in all kinds of rural schools, the normal rate of having sports class is about $87 \%$ for secondary schools, junior middle schools and central primary schools, about $82 \%$ for rural primary schools. Especially the rate of having sports class of rural primary schools and teaching schools is delightful about $76 \%$. It adequately indicated obvious increasing trend already in rate of having class in national rural middle and primary schools. But $18 \%$ of schools do not have sports class yet. $12 \%$ of sports education is in casual condition. The situation of shifting, occupying and squeezing sports class happened frequently. Especially in some junior middle schools, because graduation and promotion disregard sports performance, the schools "deprive" 9 grade students of the right of having sports class since the beginning of second semester. $37.5 \%$ of sports class has been changed into other class. The influence from exam-oriented education to having sports class objectively exists. The influence of exam-oriented pressure increases along with grade growth. The situation is quite different with the difference of region. Having enough and even sports class is the most basic requirement of school sports education, also compulsory regulation of national curriculum management. The problem of having sports class require that all levels of administrative department and schools practically establish the concept of quality-oriented education, powerfully supervise, and implement measures in place, so as to solve the problem indeed.

\subsection{Basis of Sports Education}

Today after five years of sports new curriculum reform, theoretically the trial implementation of sports curriculum standard should cover the entire middle and primary schools. When designed the question of "basis of sports education" in questionnaire survey paper, found that about $34 \%$ of rural primary school chose accordance with "sports (and health) curriculum standard" to teach, but the proportion of school choosing accordance with "sports education syllabus" is still big. $33.56 \%$ of rural junior middle school chose accordance with "sports (and health) curriculum standard" to teach, $31.07 \%$ accordance with "sports education syllabus" to teach. It adequately indicated that test, train and promotion of new curriculum reform are too far away for a large number of wide ranges of rural schools to be able to help. Teachers are the key to curriculum reform. In addition, especially worth of notice is school management in central position. The effect of school management is to provide a platform for the implement of new curriculum. The platform is good or bad, which also will determine whether or not the implement of new curriculum is successful. Implement of new curriculum standard will make higher, newer requirements for teachers in aspects of concept, knowledge and ability etc. However currently professional quality of rural sports teachers is not high generally, short professional knowledge, train less developed, short guidance, school manager ignored sports, as well as inconvenient transportation, inaccessible information, self-delay and so on, which caused the concept between new curriculum standard and sports education syllabus is not clear, theory is unknown. During class, teachers organized student to play some games if happy, ask students to run circle if unhappy, which cause sports education is in casual condition. School management lack of measures of effective inspection, 
examination, appraise and specific activity, which influence the exercise and cultivation of students body and mind.

\subsection{Setting Contents of Sports Education}

At the moment, most rural school sports use athletics events of track and field and ball games filling contents. Research showed main activity events of boys are basketball, volleyball, table tennis, badminton, long-distance running etc in middle school of rural region (85.7\%). Activity events of girls are badminton, table tennis, shuttlecock kicking, rope skipping, long-distance running etc $(79.3 \%)$. Main activity events of boys are basketball, table tennis, iron-hoop rolling, sandbag throwing etc in primary school (89.3\%). Main activity events of girls are rubber band skipping, shuttlecock kicking, hopscotch, table tennis, game playing etc in primary school (92.4\%). In recent years, content setting of rural school sports education has enlarged than before (previously most are basketball, track and field only, now added volleyball and football, some school even added martial arts, gym, badminton etc). Furthermore proportion of local traditional sports events is small in textbook. These traditional sports events are precious culture treasure accumulated in long term social practice by people, which have unique exercise value and educational effect. If this part of content extends and expands into textbook, it undoubtedly has positive effect and practical significance to supplement of content of sports education in rural school. Meanwhile, because of limitation of environment factors etc themselves, rural students have less opportunity of contacting new things compare to city. They desire to acquire new knowledge, contact new things during study, so as to experience various different fresh feelings, satisfy themselves with the study of all kinds of innovative knowledge. But, sports events setting by current education content are relatively familiar to students from small to large. So during the education process, they short activity and positivity. Teachers are used to previous education methods, short awareness of challenge and creating a new situation, which caused the great restriction of sports education in rural school.

\subsection{Sports Teaching Staff}

Now, sports teaching staff cannot reach the requirement of vast rural school yet. Additionally problems of school quotas etc. which caused that rural school have many unqualified part-time sports teachers. The total amount of full-time, part-time teachers is calculated: in average every primary school has 7.3 spots teachers. Every 125.3 students have 1 sports teacher. Every 2.78 classes have 1 sport teacher. The full-time teacher is calculated: in average every school has 1.4 sports teachers. Every 656.73 students have 1 sports teacher. Nearly every 14.6 classes have 1 sports teacher. Because of the existence of many part-time teachers, as well as feature of sports education of primary school, although proportion of full-time teachers is small, the total amount of teachers can reach the requirement of teacher's amount for sports education relatively. However existing problem is: whether or not educational quality of a large number of non-sports major part-time teachers can ensure the quality requirement of sports education? In average every school has 3.9 sports teacher in rural middle school. In average every 336.28 junior middle school students have 1 sports teacher. Each sports teacher teaches 5.84 classes sports. If each class has 3 sports classes by national regulation every week, every sports teacher would have 17.52 classes of teaching hours every week. "The ratio between teachers and students" is 1:405.09. If full-time sports teacher is calculated only, in average every 405.09 students have 1 full-time sports teacher. Each teaches 7.04 classes sports. If each class has 3 sports classes by national regulation every week, every sports teacher would have 21.12 classes of teaching hours every week. "The ratio between teachers and students" is 1:500. It adequately indicated the serious situation of shortage of sports teacher in rural junior middle school. Especially $30 \%$ of middle and primary school have no full-time sports teacher in west rural region. This serious situation has to make us think!

\subsection{Sports Field, Equipment and Fund}

Sports filed are the most basic condition of sports activity for students. Because of decrease of low grade students in primary school and adjustment of distribution structure of rural school, many schools have merged. During merge school sports activity field is ignored generally. The rate of reaching standard of sports equipment is $39.1 \%$ in rural school. In rural primary school and teaching school is 
$34 \% .21 .04 \%$ of school has no one basketball, volleyball, football field. Student's average area is about 2 square meters. At present sports fund of national rural middle and primary school is from 183 to 4132 RMB unequally. Average sports fund of middle school student is 3.41 RMB. Primary school student is $1.36 \mathrm{RMB}$. The main reason which caused this problem is the incorrect position of school sports, shortage of fund, but also related to confliction between regulation index of current sports equipment and school economic development state. It adequately indicated rural school sports developed slowly. Some "hardware" equipment of school sports are serious deficient. Although party and government paid great attention to construction of school sports field facility, more than once issued and regulated the standard in content, specification and area quota of sports field, which is different in implement. Especially difference is big between rural and city. Rural region has a big gap. The ratio of national regulation is low in rural region. Basic material condition completing school sports education task is weak, which therefore seriously affect the sports education quality and implement of various sports work. Shortage of sports facility, equipment and fund in rural school is the key restricted sports development of rural school, one big bottleneck of rural school sports.

\subsection{Student's Physical Constitution}

In August of 2006, in "the first session of china teenager physical health forum" hold in Beijing, Director Guiren Yang gave a group of data: the last national teenager physical health investigation report indicated: for 20 years teenager physical constitution declined continuously. The obesity rate of students increased fast in past 5 years. A quarter of city boys are "fatty". The ratio of myopic eyes, for junior middle school students is $50 \%$. For senior high school students is $76 \%$. For undergraduate is $83 \%$ high. Morphological development indicators of student's height, weight and chest measurement etc growth continuously, but physical capacity of vital capacity, velocity, strength, endurance etc declined continuously. Endurance quality of rural student obviously declined, but ratio of myopia raised. The main reasons caused the declined physical constitution of students are: one is modern life style caused the decreased physical activity. Two is currently exam-oriented education caused the heavy burden of student's homework, longer study time. Three is work and rest program is not suitable. Students have no time for physical exercise. Four is student's parents want kids away from embarrassed situation of "face toward soil back toward sky", and get ahead in the world. They popularly believed physical activity will influence the kid's academic record, have to force kids to give up physical exercise. Five is that supervision of all levels of functional department is not enough, without concern, consider student's physical health irrelevant.

\section{Conclusion}

Above results and analysis indicate, the actual condition of national rural school sports is worrying: $18 \%$ of school has no sports education. $12 \%$ of school sports education is in casual condition. The ratio of sports shifting into other classes is $37.5 \%$ high. $34 \%$ of primary school choose accordance with new curriculum standard to teach. $33.56 \%$ of middle school choose accordance with new curriculum standard to teach. Curriculum design mainly use athletics events of track and field and ball games etc filling the content. Teaching staff is not enough. In junior middle school "the ratio between teacher and students" is 1:500. Student's physical health is not optimistic. The physical constitution declined continuously. Seriously short of sports facility, equipment and fund. The rate of reaching standard for equipment is $39.1 \% .21 .04 \%$ of school has no basketball, volleyball and football field.

\section{Suggestion}

5.1Reinforce the study of leaders of all levels of education administrative department, improve their ideas and understanding, especially the functional department supervised school sports work. On height of education strategic development, must completely understand the significance of strengthening rural school sports, move the work focus onto this area. Strive together to solve difficulty, practically manage rural school sports work as priority responsibility. 
5.2Establish and complete supervision system, monitoring system of student's physical constitution and evaluation system of sports examination for rural school sports. Build comprehensive, continuous evaluation system for school sports work and student's physical health condition. As the important content of student growth record, student's sports and health will be filed into student profile for reference of graduation and promotion. In all kinds of evaluation, election, indicators of school sports and teenager health shall have certain proportion until implement of one vote veto.

5.3Reinforce the construction of teaching staff of rural sports. All levels of education administrative department evaluate quotas of middle and primary school sports teachers again based on the practice of substantial increasing teaching hours of sports in basic education curriculum reform, train all current sports teachers in turns. The system of pre-job training, employment with certificate shall be implement for part-time sports teachers in middle and primary school. Meanwhile protect legal rights of sports teachers, implement labor protection of outdoor work and appropriately increase the ratio of evaluation and appraise for sports teachers.

5.4All levels of education administrative department shall reinforce input of school sports fund. School public fund shall be used for school sports work at certain ratio. Condition guarantee of rural school sports is the input point of school sports fund, bring into new protection mechanism of rural compulsory education. Meanwhile, rural school shall adjust to local condition, make things done simply, start with local method, and merge with outside together, develop and take full advantage of all kinds of current sports resource.

5.5Rural school sports teachers shall improve professional skills and moral cultivation themselves, learn how to study, think, accumulate, reform, breakthrough and innovate. As sports teachers improve in profession and thoughts continuously, positively work, study hard, think over the work only, they would accumulate continuously and improve concept. They should consider work as platform of study and research, consider sports as his own lifetime career, and instead consider sports as his own way of making living. Consequently, national rural school sports can get out of trouble, complete and develop.

\section{References}

[1] Zonghu Qu, quality education and rural school sports [M], Guizhou Education Press, 1999.

[2] Guiren Yang, actual condition of teenager physical health and countermeasure [R], the first session of china teenager physical health forum, 2006

[3] Zhaoxiang Wu, modern school sports science [M], Anhui University Press, April 2004

[4] Zhongyi Kong, Practice and Think to "National Students Physical Health Standard" [J], China School Sports, 2008 (5), Page 14-15

[5] Data Management Center of National "Student Physical Health Standard", Data Statistic and Analysis Report of National "Student Physical Health Standard” 2005 [J], China School Sports, 2006 (5), Page 10-14 